\title{
Prognostic factors for survival after neoadjuvant chemotherapy for advanced ovarian cancer: meta-analysis
}

\author{
Malcolm John Farquharson $^{{ }^{*}}$, Nadeem Ahmed Siddiqui ${ }^{2}$ \\ ${ }^{1}$ Department of Obstetrics and Gynecology, Crosshouse Hospital, Ayrshire, UK. \\ ${ }^{2}$ Department of Gynecological Oncology, Glasgow Royal Infirmary, Glasgow, UK. \\ E-mail: *malcolmfarquharson@nhs.net
}

Received 25 July 2011; revised 20 August 2011; accepted 29 August 2011.

\section{ABSTRACT}

Background: In advanced disease current practice is staging and primary debulking laparotomy followed by platinum-based chemotherapy. The effort to achieve 'optimal debulking' is associated with a complication risk of $8 \%-63 \%$ and a mortality rate of $1 \%$ $6 \%$. Neoadjuvant chemotherapy has been proposed as an alternative option. Objectives: This meta-analysis aimed to determine prognostic factors influencing survival in patients with advanced ovarian cancer following neoadjuvant chemotherapy. Search Strategy: Clinical trials citing the terms 'advanced ovarian cancer', 'ovarian cancer', 'neoadjuvant chemotherapy' and 'surgery' were identified by searching Pubmed and ScienceDirect between January 1st 2000 and September 30th 2010. Data Collection and analysis: The trials included used platinum-based chemotherapy and involved stage III/IV disease that underwent neoadjuvant chemotherapy followed by surgery. Prognostic variables were identified for analysis including number/type of chemotherapy, \% stage IV disease, \% maximal cytoreductive surgery and whether a lymphadenectomy was performed. The \% bowel surgery and ultra-radical surgery was also analysed. Main Results: Twenty six trials were identified as suitable for analysis and included 3 non-randomised Phase II studies, 2 retrospective case-control studies, 17 from retrospective analysis and 1 RCT. A significant association between taxane use vs platinum only $(p=0.019)$, year of publication $(p=0.032)$, \% maximal interval cytoreduction $(p=0.046)$ and median overall survival was identified. No significant survival benefit was demonstrated with number of chemotherapy cycles $(p=$ 0.065), lymphadenectomy $(p=0.813)$ and $\%$ bowel surgery performed $(p=0.606)$. Conclusions: The addition of taxane and \% maximal cytoreduction achieved is associated with improved overall survival. There is, however no evidence that lymphadenecto- my, number of chemotherapy cycles or bowel surgery influences survival.

Keywords: Neoadjuvant Chemotherapy; Survival; Advanced Ovarian Cancer; Prognostic Factors

\section{INTRODUCTION}

Ovarian cancer is the 2nd commonest gynaecological malignancy with epithelial tumours accounting for $90 \%$. In the UK, there are approximately 6500 new cases of ovarian cancer per year. They are usually discovered at an advanced stage (FIGO stage III/IV) resulting in the overall poor prognosis [1]. The 5 year survival rate for early stage cancer is about $90 \%$ whereas the 5 year survival rate in advanced disease is $10 \%-30 \%$ [2].

In advanced ovarian disease the standard current practice is a staging and primary debulking laparotomy followed by platinum based chemotherapy [3]. Optimal cytoreduction during initial surgery has become widely accepted as the most important prognostic indicator.

Over the last 20 years the view on what constitutes 'maximal debulking' has changed from leaving no tumour deposit $>2 \mathrm{~cm}$ to leaving no macroscopic disease being acceptable. Increasingly more radical surgery is being performed in an effort to free the patient of macroscopic disease [4]. A meta-analysis of 2637 women from retrospective non-randomised control trials demonstrated a survival benefit for those patients with advanced disease who had no macroscopic disease or tumour deposit $>2 \mathrm{~cm}$ [5].

There has been no evidence that a survival benefit exists with residual tumour $>2 \mathrm{~cm}$ and often optimal debulking is simply not possible due to the extent of the disease [6]. In this scenario initial surgery may be questionable if residual tumour $<2 \mathrm{~cm}$ is not achievable.

The effort to achieve 'maximal/optimal debulking' is associated with a complication risk of $8 \%$ - 63\% [7]. Mortality following debulking surgery has been reported from $1 \%-6 \%$ with a recent systematic review reporting 
the mean mortality at $2.8 \%$ [8]. A laparotomy is a major operation that requires hospital admission and time for recovery that may delay the start of chemotherapy. However two studies have shown no evidence that a delay in starting chemotherapy influences the survival rate $[9,10]$.

Neoadjuvant chemotherapy has been proposed as an alternative option in advanced ovarian cancer. A recent RCT showed that neoadjuvant chemotherapy was not inferior to primary debulking surgery in terms of the survival rate [4]. It can be argued that surgery following chemotherapy may be technically easier than if surgery was undertaken initially. In addition a prospective study has shown that there is an improved patient quality of life and functional status following neoadjuvant chemotherapy [11].

The survival benefit and prognosis of upfront surgery in advanced ovarian cancer is well known and established. However the use of neoadjuvant chemotherapy is less well researched. The aim of this meta-analysis is to determine the prognostic factors influencing overall survival rate in patients with advanced ovarian cancer following neoadjuvant chemotherapy.

\section{METHODS}

A meta-analysis was performed based on the recommendations of the Preferred Reporting Items for Systematic Reviews and Meta-analyses (PRISMA) statement [12].

\subsection{Search Strategy}

A literature search has been carried out using the National Library of Medicine and National Institutes of Health (Pubmed) and ScienceDirect for all clinical trials on the use of neoadjuvant chemotherapy in advanced ovarian cancer. The following headings and keywords were used in the literature search; 'advanced ovarian cancer', 'ovarian cancer', 'neoadjuvant chemotherapy' and 'surgery'. The search included all English language articles and was limited to the period of January 1st 2000 to September 30th 2010.

The references of each article were reviewed for any relevant articles which were subsequently included in the analysis. The terms have been expanded to include all subcategories in an attempt to obtain all published trials that fit the selection criteria.

\subsection{Selection Criteria}

The trials included have used platinum based chemotherapy and involve advanced epithelial ovarian cancer stage III/IV that was staged according to the FIGO classification. The cohorts included must have undergone neoadjuvant chemotherapy followed by cytoreductive surgery.
The excluded trials were those where chemotherapy regimens other than platinum based were used, early stage ovarian cancer and no inclusion of the proportion of patients with stage III or IV disease. Articles were excluded that did not include the median survival time (months). Also excluded were articles that did not mention criteria for residual tumour and define what they considered optimal debulking surgery. Further cohorts were not included if the number of chemotherapy cycles administered and the different chemotherapy regimens were not recorded.

\subsection{Studies Identified}

A total of 333 potentially relevant studies were identified based on the above search criteria. After screening the titles and abstracts, 291 studies were excluded for the following reasons: (1) unrelated to subject $(n=115),(2)$ review articles ( $n=96)$, (3) non ovarian patients $(n=60)$, (4) case reports $(n=15),(5)$ preclinical trials $(n=5)$. Further assessment of these studies for more detailed information identified 16 ineligible studies due to intraperitoneal or intra-arterial chemotherapy $(\mathrm{n}=8)$, no median overall survival $(\mathrm{n}=5)$, no residual tumour criteria $(\mathrm{n}=2)$ and the use of adjuvant chemotherapy $(\mathrm{n}=1)$. Finally 26 studies were identified as suitable for inclusion in the meta-analysis (Figure 1).

\subsection{Extraction of Data}

The baseline characteristics of patients were recorded including the median and range of age, the histology and grade of disease and the number of patients within each cohort. The percentage of patients with stage III/IV disease were recorded as well as a breakdown of Stage IIIA, B and C if included. The residual tumour criteria of each study was identified and maximal cytoreduction was considered to have occurred if residual disease measured less than $1 \mathrm{~cm}$ in largest diameter.

Additional information included the study design and the year of study. The staging procedure used to diagnose and determine severity were collected and also the preoperative disease severity including the main site of disease.

Other information included percentage of patients achieving maximal debulking within the cohort, rate of bowel surgery performed, whether or not lymphadenectomy was performed and the site of the residual disease following debulking surgery. The percentage of patients in each cohort who did not go on to have cytoreductive surgery following neoadjuvant chemotherapy was recorded and the outcomes of these patients.

Whether ultra radical surgery was done or not among the cohorts was collected in addition to what procedures were performed. 


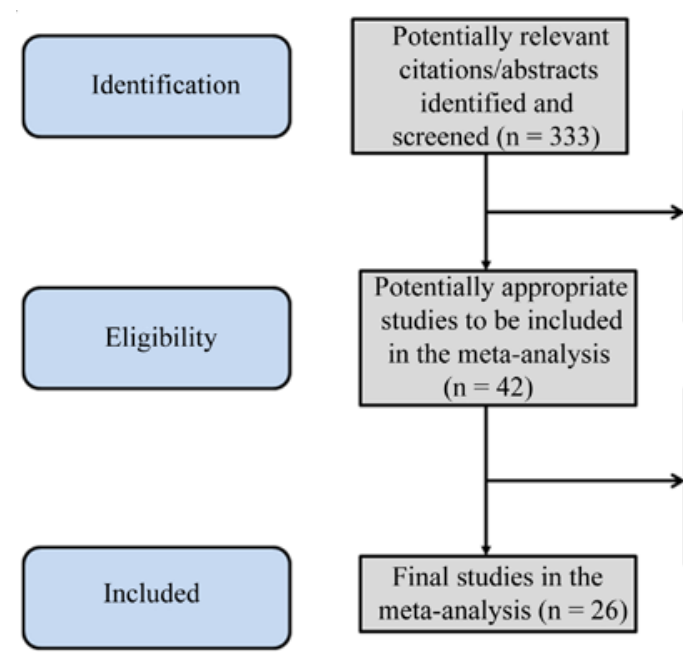

Citations excluded $(\mathrm{n}=291)$

$>$ Unrelated $(\mathrm{n}=115)$

$>$ Review articles $(\mathrm{n}=96)$

$>$ Non-ovarian disease $(\mathrm{n}=60)$

$>$ Case report $(\mathrm{n}=15)$

$>$ Preclinical study $(\mathrm{n}=5)$

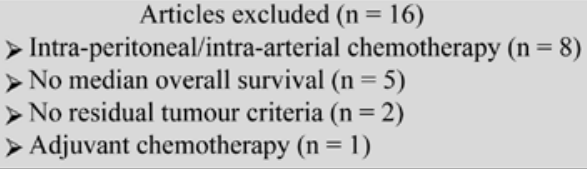

Figure 1. Studies identified—flow diagram.

The chemotherapy administered and number of cycles, including the percentage taxane use verses platinum only chemotherapy, were collected. The overall median survival and progression free survival in months was recorded.

The region in which the cohort was undertaken was recorded for comparison within the analysis.

\subsection{Statistical Analysis}

Sub-analysis was done on a number of prognostic factors including the extent of debulking surgery, percentage stage IV disease, whether or not lymphadenectomy was performed and age with respect to survival benefit. In addition the pre-operative severity, percentage of bowel resection performed, site of residual tumour and percentage of ultra-radical surgery performed among the cohorts was analysed. A comparison of maximal debulking and the median overall survival rates between regional centres was also analysed.

Statistical methods included simple linear regression models to analyse the data with bubble charts corresponding to the number of patients in each cohort and $\mathrm{p}$ $<0.05$ was considered statistically significant. The analysis was carried out using Mini Tab 16, a statistical software package.

\section{RESULTS}

\subsection{Clinical Characteristics}

A total of 26 studies were identified following the literature search as meeting the inclusion criteria and suitable for meta-analysis. The clinical characteristics of the studies are outlined in Tables $\mathbf{1}$ and 2. Three cohorts were from non-randomised Phase I studies; 3 cohorts were from non-randomised Phase II studies; 2 cohorts were from retrospective case control studies; 17 were from retrospective analysis and 1 was a randomised control trial. The mean number of patients in each cohort was 64 ( median $=46.5$, range $=17-334$ ).

The majority of the studies had serous histological type with a mean percentage of $70.4 \%$ (range $=25.9 \%$ $95 \%$ with the remainder including mucinous, endometrioid, undifferentiated, unspecified adenocarcinoma and clear cell histology types.

The percentage grade 3 and 4 was identified in 17 of the 26 cohorts and the mean percentage Grade 3 and 4 was $64.6 \%$ (range $=27 \%$ - 90.9\%). Median survival time ranged from 18 to 52 months with the mean of all the cohorts as 32.1 months. Progression free survival rates were recorded in 16 of the 26 cohorts and the mean was 16.5 months (range $=12-25.4$ months).

The residual tumour criteria which was the optimal residual disease following debulking surgery ranged from $<1 \mathrm{~cm}$ to $<2 \mathrm{~cm}$ between cohorts. Between $2000-2005$ the residual tumour criteria was $<2 \mathrm{~cm}$ in $62 \%$ of cohorts compared to 31\% between 2006-2010. During the period 2006-2010, the residual tumour criteria was $>1 \mathrm{~cm}$ in $69 \%$ of cohorts.

\subsection{Neoadjuvant Chemotherapy}

The mean number of pre-operative chemotherapy cycles received prior to surgery between the cohorts was 3.6 (range $=2.5-6$ ). All cohorts used platinum based chemotherapy and twenty three cohorts used taxane as part of the chemotherapy regime. The mean percentage of patients receiving taxane per cohort was $77.6 \%$ with a range of $0 \%$ to $100 \%$.

Simple linear regression shows an increase of 3.7 months in the median survival time for every single increase in chemotherapy cycle. The Pearson correlation was $r=+0.37$. However there was a non-significant 
Table 1. Study characteristics.

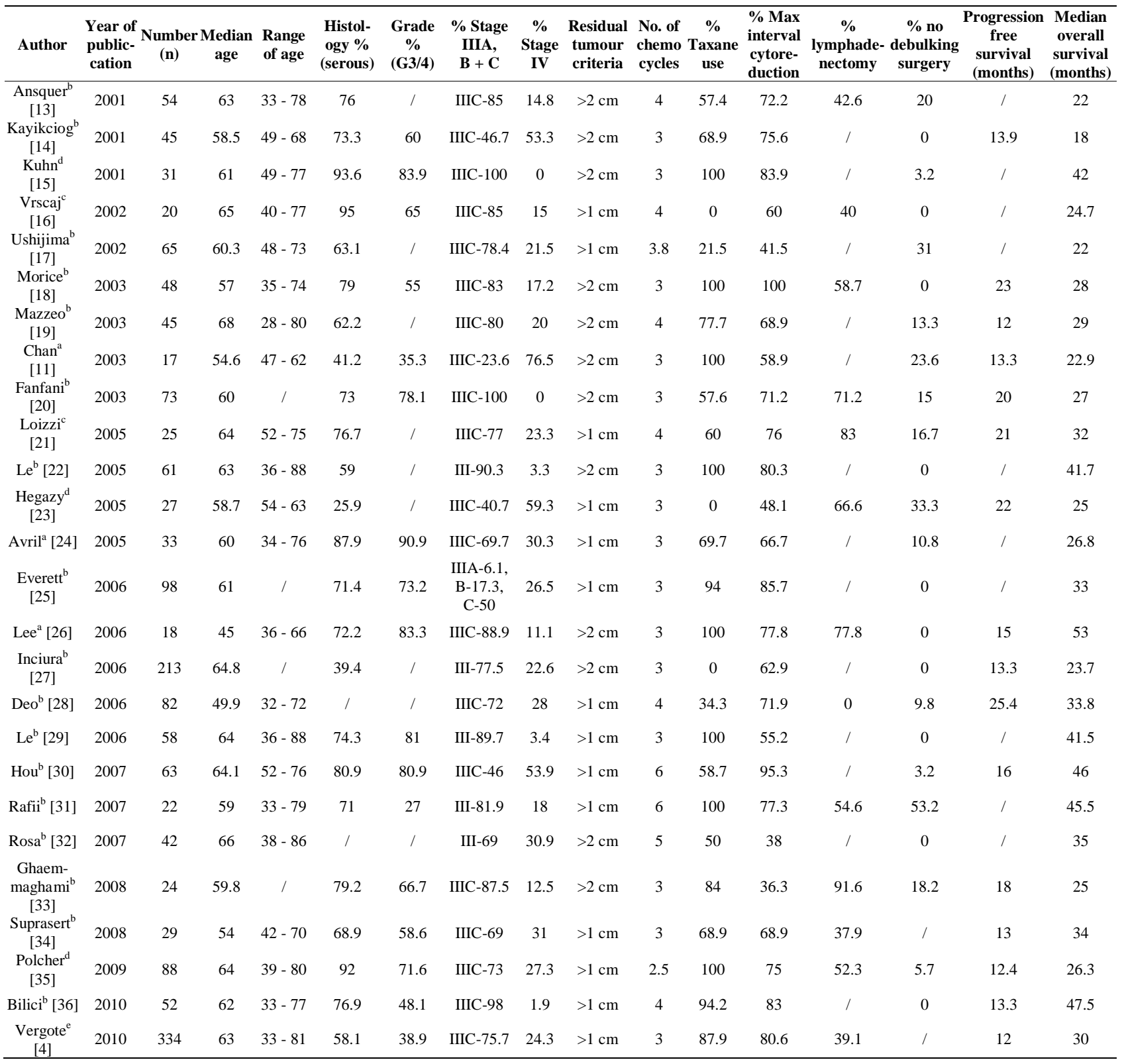

${ }^{\mathrm{a}}$ Phase I study; ${ }^{\mathrm{b}}$ Retrospective analysis; ${ }^{\mathrm{c}}$ Retrospective case-control study; ${ }^{\mathrm{d}}$ Phase II study; ${ }^{\mathrm{e}}$ Randomised control trial.

trend towards increased survival with increasing number of chemotherapy cycles ( $\mathrm{p}=0.065)$ (Figure 2$)$.

There was a statistically significant association between percentage taxane use and the overall survival rate ( $p=0.019$ ) (Figure 3). For every 10\% increase in taxane use there was a 1.27 month increase in the survival rate. There was a strong correlation $\mathrm{r}=+0.46$.

\section{3. \% Stage IIIC and IV}

The majority of the cohorts were stage IIIC disease with a range of $23.6 \%$ - $100 \%$ and a mean of $74.5 \%$. One cohort broke the staging down into stage IIIA, B and C with $6.1 \%, 17.3 \%$ and $50 \%$ respectively present within the cohort.

The mean percentage of patients with Stage IV disease per cohort was $24.1 \%$ with a range from $0 \%-76.5 \%$. Two cohorts involved 100\% Stage IIIC and did not have any patients with stage IV disease within the cohort. Analysis showed that for every $10 \%$ increase in stage IV disease there was a 1.8 month decrease in the overall survival rate. Simple linear regression showed a nonsignificant trend towards decreased survival with increasing \% stage IV disease $(p=0.065)$ (Figure 4). There was a negative correlation $\mathrm{r}=-0.37$. 
Table 2. Results from studies included in the meta-analysis.

\begin{tabular}{|c|c|c|c|c|c|c|}
\hline Author & Staging procedure & Pre-op disease severity & Ultra-radical surgery & $\begin{array}{c}\text { Rates of } \\
\text { bowel } \\
\text { surgery \% }\end{array}$ & Residual tumour site & Nationality \\
\hline Ansquer [13] & $\begin{array}{c}\text { Laparoscopy (61\%), } \\
\text { Laparotomy (39\%) }\end{array}$ & l & $\begin{array}{c}\text { Diaphragm stripping - 5.6\%, } \\
\text { Splenectomy - 3.7\%, } \\
\text { Cholecystectomy - 1.9\%, } \\
\text { Partial pancreatic } \\
\text { resection - } 1.9 \%\end{array}$ & 9.3 & $\begin{array}{c}\text { Peritoneum - 33.3\%, } \\
\text { liver serosa - 26.7\%, } \\
\text { subdiaphragmatic - } \\
\text { 20\%, } \\
\text { colon serosa - } 20 \% \text {, } \\
\text { small bowel - } 13.3 \% \text {, } \\
\text { spleen serosa - } 8.9 \% \text {, } \\
\text { douglas - } 22.4 \%\end{array}$ & $\begin{array}{l}\text { Europe - } \\
\text { France }\end{array}$ \\
\hline Kayikciog [14] & CT + Biopsy & $\begin{array}{l}\text { Upper abdominal } \\
\text { disease - } 55.6 \%\end{array}$ & $0 \%$ & 2.2 & l & $\begin{array}{l}\text { Europe - } \\
\text { Turkey }\end{array}$ \\
\hline Kuhn [15] & Laparoscopy & l & I & 29 & l & $\begin{array}{l}\text { Europe- } \\
\text { Germany }\end{array}$ \\
\hline Vrscaj [16] & $\begin{array}{l}\text { Laparoscopy or } \\
\text { Laparotomy }\end{array}$ & l & $0 \%$ & 0 & l & $\begin{array}{l}\text { Europe - } \\
\text { Slovenia }\end{array}$ \\
\hline Ushijima [17] & / & l & / & / & / & Asia - Japan \\
\hline Morice [18] & $\begin{array}{l}\text { Laparoscopy (21\%), } \\
\text { Laparotomy }(72 \%) \\
\text { CT + Biopsy }(7 \%)\end{array}$ & l & $\begin{array}{l}\text { Diaphragm stripping - 16\%, } \\
\text { Splenectomy - 5\%, } \\
\text { Permanent enterostomy - 5\% }\end{array}$ & 19 & l & $\begin{array}{l}\text { Europe - } \\
\text { France }\end{array}$ \\
\hline Mazzeo [19] & $\begin{array}{l}\text { Laparoscopy } \\
(71.1 \%), \\
\text { CT + Biopsy } \\
(28.9 \%)\end{array}$ & l & l & l & l & $\begin{array}{l}\text { Europe - } \\
\text { Belgium }\end{array}$ \\
\hline Chan [11] & CT scan & $\begin{array}{c}\text { Pleural effusion - } 41 \% \text {, } \\
\text { Liver mets - } 23.6 \% \text {, } \\
\text { Lung mets - 5.9\%, } \\
\text { Chest wall mets - 5.9\% }\end{array}$ & / & 11.8 & / & Asia - China \\
\hline Fanfani [20] & Laparotomy (100\%) & $\begin{array}{l}\text { Upper abdominal disease - } \\
9.8 \% \text {, Portal triad disease - } \\
12.8 \% \text {, } \\
\text { Diaphragm disease - } 32.4 \%\end{array}$ & / & / & l & $\begin{array}{l}\text { Europe - } \\
\text { Italy }\end{array}$ \\
\hline Loizzi [21] & / & l & / & l & / & $\begin{array}{l}\text { Europe - } \\
\text { Italy }\end{array}$ \\
\hline Le [22] & $\begin{array}{l}\mathrm{CT}+\text { USS-guided } \\
\text { biopsy }\end{array}$ & $\begin{array}{c}\text { Upper abdominal disease - } \\
6.6 \% \text {, solely pelvic disease - } \\
42.6 \%\end{array}$ & / & l & $\begin{array}{c}\text { pelvis - } 27.9 \% \text {, } \\
\text { upper abdomen - } 18 \% \text {, } \\
\text { pelvis + upper abdomen } \\
\text { - } 27.9 \%\end{array}$ & $\begin{array}{l}\text { N.America - } \\
\text { Canada }\end{array}$ \\
\hline Hegazy [23] & $\begin{array}{l}\text { Laparoscopy } \\
\text { (62.9\%), } \\
\text { Laparotomy } \\
(37.1 \%)\end{array}$ & l & $\begin{array}{l}\text { Bladder resection - 5.6\%, } \\
\text { Splenectomy - } 5.6 \%\end{array}$ & 16.7 & l & USA \\
\hline Avril [24] & Laparoscopy (100\%) & l & I & l & I & USA \\
\hline Everett [25] & / & l & 1 & 16.3 & I & USA \\
\hline Lee [26] & $\begin{array}{l}\text { Laparoscopy, } \\
\text { Laparotomy or } \\
\text { CT-guided biopsy }\end{array}$ & l & $0 \%$ & 5.6 & I & $\begin{array}{l}\text { Asia - } \\
\text { S.Korea }\end{array}$ \\
\hline Inciura [27] & CT scan & l & I & I & I & $\begin{array}{l}\text { Europe - } \\
\text { Lithuania }\end{array}$ \\
\hline Deo [28] & $\begin{array}{c}\mathrm{CT}+\text { cytology }(75 \%), \\
\text { laparotomy } \\
(25 \%)\end{array}$ & I & I & 7.4 & I & Asia - India \\
\hline Le [29] & $\begin{array}{c}\mathrm{CT}+\text { USS-guided } \\
\text { biopsy }\end{array}$ & l & - & 3.4 & I & $\begin{array}{l}\text { N.America - } \\
\text { Canada }\end{array}$ \\
\hline Hou [30] & CT + cytology & $\begin{array}{c}\text { Only pleural effusion - 53.9\%, } \\
\text { disease limited to } \\
\text { abdomen - } 46 \%\end{array}$ & $\begin{array}{c}\text { Splenectomy - 0\%, } \\
\text { Pancreatectomy - 0\%, } \\
\text { Gallbladder resection - 1.6\%, } \\
\text { Liver resection - 0\%, } \\
\text { Appendectomy - 3.2\% }\end{array}$ & 4.8 & / & USA \\
\hline
\end{tabular}




\begin{tabular}{|c|c|c|c|c|c|c|}
\hline Rafii [31] & / & l & I & 2.9 & l & $\begin{array}{l}\text { Europe - } \\
\text { France }\end{array}$ \\
\hline Rosa [32] & I & l & / & / & l & Europe - UK \\
\hline $\begin{array}{l}\text { Ghaemmaghami } \\
\text { [33] }\end{array}$ & Laparotomy (100\%) & l & l & l & / & Asia-Iran \\
\hline Suprasert [34] & / & $\begin{array}{c}\text { Pelvis - 51.7\%, } \\
\text { Abdomen - } 13.8 \% \text {, } \\
\text { Abdomen + pelvis - 34.5\%, } \\
\text { Lung mets - } 20.7 \% \text {, } \\
\text { Liver mets - } 6.9 \% \text {, } \\
\text { Splenic mets - 3.4\% }\end{array}$ & / & 3.4 & / & $\begin{array}{l}\text { Asia - Thai- } \\
\text { land }\end{array}$ \\
\hline Polcher [35] & $\begin{array}{c}\text { Laparoscopy } \\
\text { (77.2\%), } \\
\text { Laparotomy (18.2\%) }\end{array}$ & / & $\begin{array}{l}\text { Upper abdo surgical proce- } \\
\text { dures - } 30.1 \%\end{array}$ & 36.1 & l & $\begin{array}{l}\text { Europe - } \\
\text { Germany }\end{array}$ \\
\hline Bilici [36] & $\begin{array}{c}\text { CT + biopsy, } \\
\text { Laparotomy or } \\
\text { Laparoscopy }\end{array}$ & / & l & l & / & $\begin{array}{l}\text { Europe - } \\
\text { Turkey }\end{array}$ \\
\hline Vergote [4] & $\begin{array}{l}\text { Laparotomy (3.6\%), } \\
\text { Laparoscopy (34.7\%) }\end{array}$ & l & Splenectomy - 4\% & 8.7 & $\begin{array}{c}\text { Diaphragm - 26.4\%, } \\
\text { liver serosa - } 10.2 \% \text {, } \\
\text { omentum - } 13.6 \% \text {, } \\
\text { intestines - } 22 \% \text {, } \\
\text { peritoneal - } 25.8 \% \text {, } \\
\text { pelvis - } 22.4 \% \text {, } \\
\text { spleen - 3.4\% }\end{array}$ & International \\
\hline
\end{tabular}

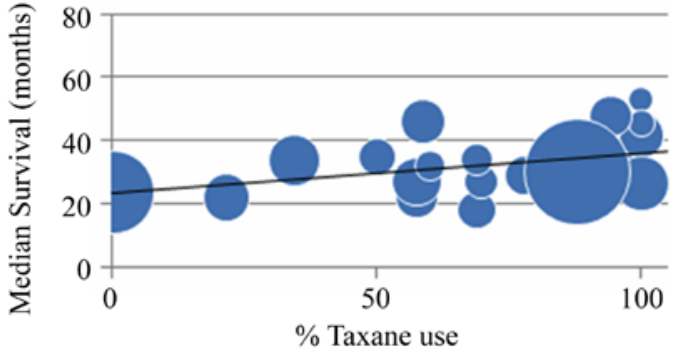

Figure 2. Survival time against \% taxane use.

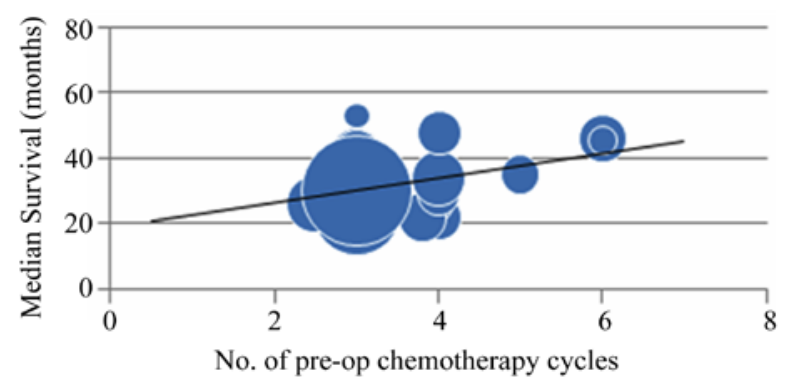

Figure 3. Survival time against No. of chemotherapy cycles.

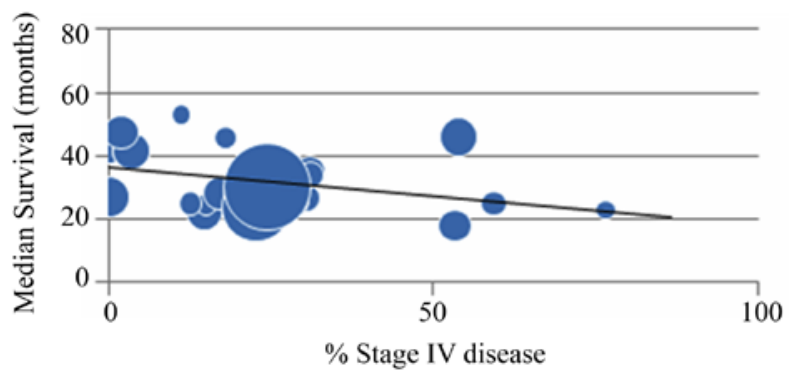

Figure 4. Survival time against \% stage IV disease.

\subsection{Year of Publication and Median Cohort Age}

13 of the 26 cohorts (50\%) were published between 2001 - 2005 with the remaining 13 cohorts between 2006-2010. A statistical significance was identified between the year of publication and the overall survival rate $(p=0.032)$ (Figure 5). Analysis showed that for every year increase in publication there was a 1.46 month increase in the overall survival rate. There was a positive corre- lation $\mathrm{r}$ $=+0.42$.

The mean percentage maximal cytoreduction achieved between 2000 - 2005 was $69.5 \%$ compared to $69.8 \%$ between 2006-2010.

The mean of the median age was 60.4 years among the cohorts (range $=45-68$ years). On further analysis no statistical significance was found between median age and the overall survival rate $(\mathrm{p}=0.312)$ (Figure 6). There was a negative correlation $r=-0.21$.

\subsection{Maximal Cytoreductive Surgery}

The distribution amongst cohorts in terms of definition of maximal debulking was as follows: $<2 \mathrm{~cm}$ in $46.2 \%$ and $<1 \mathrm{~cm}$ in $53.8 \%$. The mean percentage of maximal cytoreductive surgery for all cohorts was $69.7 \%$, with a range from $36.3 \%$ to $100 \%$. A statistical significance was found between percentage maximal cytoreductive surgery and the overall survival rate $(p=0.046)$ (Figure 7). On further analysis it showed that for every $10 \%$ increase in \% maximal cytoreductive surgery there was a 2.28 month increase in the overall survival rate. There was a strong positive Pearson correlation $r=+0.40$.

\subsection{Lymphadenectomy}

Lymphadenectomy was recorded in 12 of the 26 cohorts. 


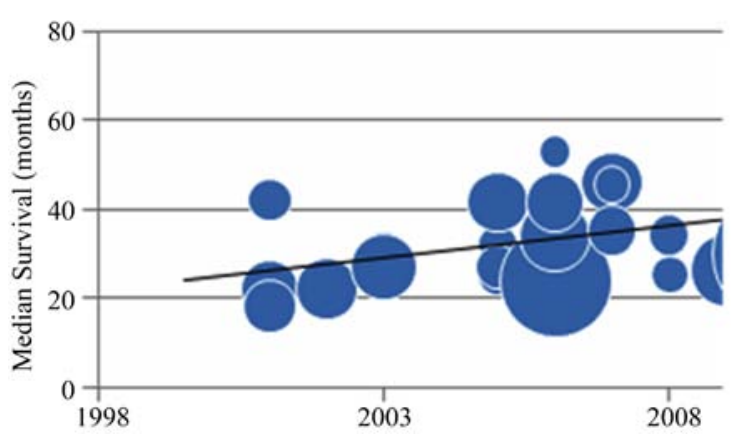

Figure 5. Survival time against year of publication.

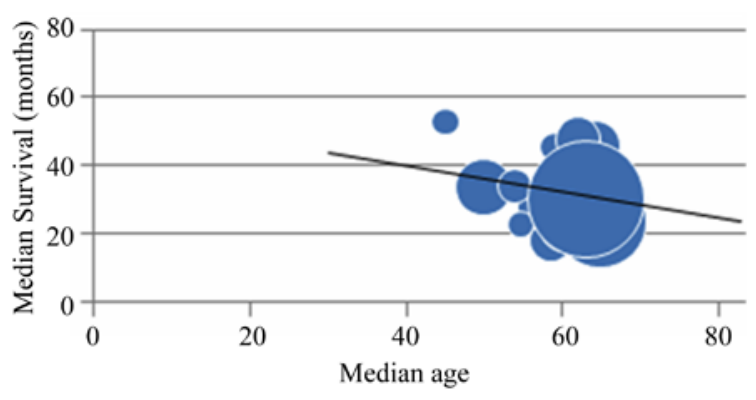

Figure 6. Survival time against median age of patients.

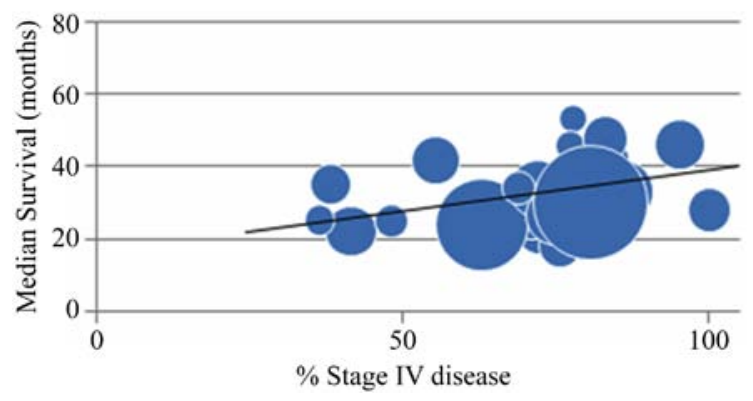

Figure 7. Survival time against \% maximal cytoreduction achieved.

In the remaining 14 cohorts it was unclear whether lymphadenectomy was performed or not as part of the debulking surgery.

The mean percentage of lymphadenectomy performed among the 12 cohorts was 55\%, with a range from $0 \%$ to $91.6 \%$. No statistical significance was found between the percentage lymphadenectomy performed and the overall survival rate $(p=0.813)$ (Figure 8). There was a weak positive correlation $\mathrm{r}=+0.07$.

\subsection{Comparison between Centres}

The cohort studies were from a broad range of countries from Europe, Asia and North America. Twelve of the cohorts were from Europe, 7 were from Asia, 6 were from North America and the recent randomised control trial from Vergote et al. [4] was an international paper. The mean of the overall survival rate was 31.9 months in

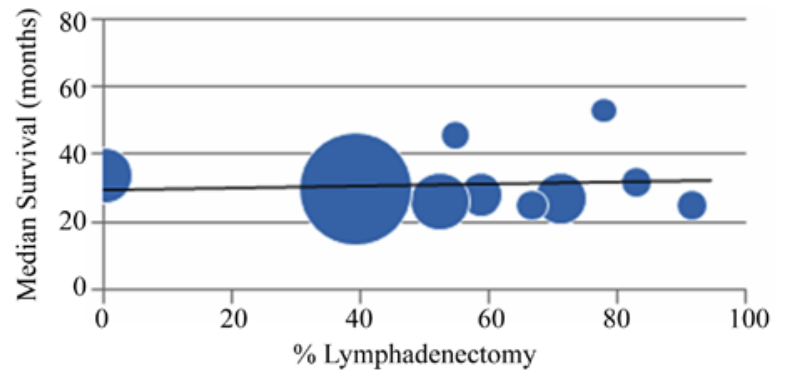

Figure 8. Survival time against \% of Lymphadenectomy performed among the cohorts.

Europe, 29.8 months in Asia and 35.6 months in North America (Figure 9).

The percentage of maximal cytoreduction achieved between the centres was $72.4 \%$ in Europe, 61.6\% in Asia and 71.8\% in North America (Figure 10).

Lymphadenectomy was performed in 7 of the 12 European cohorts (58\%), in 3 of the 7 Asian cohorts (43\%) and in 1 of the 6 North American cohorts (17\%).

\subsection{Bowel Resection and Ultra Radical Surgery}

The percentage of bowel resections performed among the cohorts ranged from $0 \%-36.1 \%$. Sixteen of the 26 cohorts recorded whether bowel resection was performed or not. Two studies differentiated bowel resection as large or small bowel and one study identified the site of resection as a rectosigmoid resection. The mean bowel resection rate was $9.8 \%$ between cohorts.

Further analysis showed that for every $10 \%$ increase in percentage bowel surgery there was a decrease of 1.4 months in the overall survival rate. There was no statistically significant relationship found between the median overall survival rate and percentage bowel surgery performed $(p=0.606)$. There was a weak correlation $r=$ -0.14 .

The mean percentage maximal cytoreduction achieved among the cohorts that performed bowel surgery was $74.2 \%$ compared to the remaining cohorts that did not mention or perform bowel surgery of $62.5 \%$. There was a higher percentage of Stage IV disease of $28.7 \%$ in the cohorts that performed bowel surgery compared to $16.7 \%$ in those cohorts that did not perform the surgery.

Nine of the 26 cohorts mentioned if ultra radical debulking surgery was performed. Six of the nine studies actually performed ultra radical surgery. A variety of procedures were performed amongst the cohorts including splenectomy, cholecystectomy, diaphragm stripping, permanent enterostomy, bladder resection, liver resection, appendicectomy and pancreatectomy. One study just mentioned upper abdominal surgical procedures and did not specify the individual procedures. The rate of splenectomies performed ranged from $0 \%-5.6 \%$, with a mean 


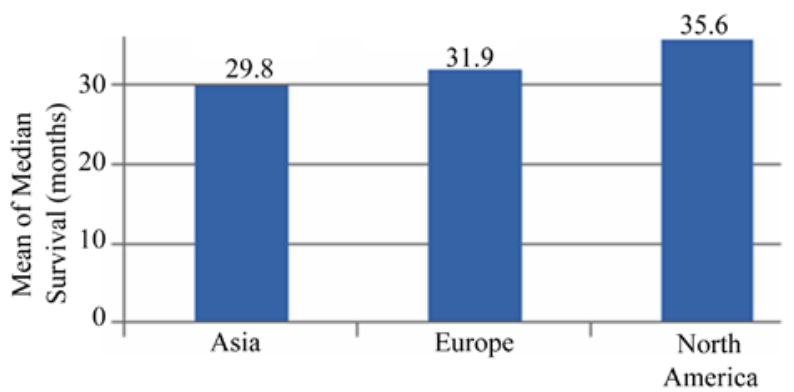

Figure 9. Survival between the centres.

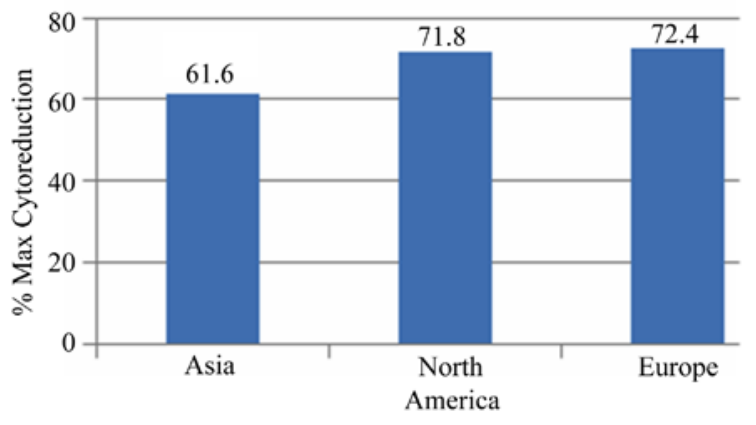

Figure 10. \% Maximal cytoreduction achieved between the centres.

of $3.7 \%$. Diaphragmatic stripping ranged from $5.6 \%$ to $16 \%$.

The percentage maximal debulking ranged from $48.1 \%-100 \%$ in the cohorts that performed ultra radical surgery with a mean of $78.5 \%$. In the cohorts that performed ultra radical surgery the mean overall survival rate was 29.6 months with a range from 22 to 46 months.

\subsection{Staging Procedure}

Twenty cohorts out of 26 mentioned the method of staging used to establish the diagnosis and severity of the disease. The methods included laparoscopy, laparotomy, CT + biopsy, CT + ultrasound guided biopsy, CT + cytology and CT scan only. The majority of cohorts used either laparoscopy or laparotomy with 12 out of 20 and 11 out of 20 cohorts respectively using this method of staging. One cohort used CT scan for staging but was unclear if a biopsy or cytology was performed. The remaining six cohorts did not mention the staging procedure.

\subsection{Pre-Operative Severity}

Only 6 out of the 26 cohorts mentioned the severity of disease prior to neoadjuvant chemotherapy and debulking surgery 5 of these 6 cohorts involved some degree of upper abdominal disease. The percentage of upper abdominal disease ranged from $6.6 \%$ to $55.6 \%$. 2 cohorts recorded the presence of lung metastasises $(5.9 \%$ and 20.7\%). 1 cohort recorded the presence of portal triad disease (12.8\%). 2 cohorts differentiated between the presence of abdominal disease and pelvic disease.

The cohort that had 55.6\% upper abdominal disease achieved maximal debulking in $75.6 \%$. No ultra radical surgery was noted as being performed. The median overall survival rate in this cohort was 18 months, which was the lowest survival rate amongst the cohorts, compared to a mean overall survival rate between the cohorts of 32.1 months. There were 2 cohorts that mentioned the presence of lung metastasises, the cohort with $5.9 \%$ of lung metastasises present achieved maximal debulking in $58.9 \%$ and the overall survival rate was 22.9 months. This compared to the other cohort with lung metastasises present in $20.7 \%$ that had maximal debulking achieved in $68.9 \%$ and the overall survival rate was 34 months. The \% stage IV disease between these cohorts was $76.5 \%$ and $31 \%$ respectively. Ultra radical surgery was not noted as being performed in either of these cohorts.

\subsection{Residual Tumour Site}

The residual tumour site following neoadjuvant chemotherapy and debulking surgery was recorded in only 3 of the 26 cohorts. One of these cohorts identified the site of residual tumour as pelvis, abdomen or pelvis + abdomen and the remaining 2 cohorts identified the specific site.

\subsection{Percentage of No Debulking Surgery}

24 of the 26 cohorts noted the percentage of patients that did not go on to have debulking surgery following neoadjuvant chemotherapy. The percentage not receiving debulking surgery ranged from $0 \%-53.3 \%$ with a mean of $9.5 \%$. In ten cohorts debulking surgery was performed on all the patients. The cohort that had 53.3\% of patients not going on to receive debulking surgery had a median overall survival rate of 45.5 months, the highest survival rate among the cohorts. The percentage maximal debulking was $77.3 \%$ in this cohort and $18 \%$ of the patients had stage IV disease. No ultra radical surgery was done on this cohort.

\subsection{Outcome Following No Debulking Surgery}

Only 7 cohorts recorded the outcome in those patients that did not go on to have debulking surgery following neoadjuvant chemotherapy. These have been listed in the following table (Table 3). The most common outcome in 4 of the 7 cohorts was disease progression following neoadjuvant chemotherapy.

\section{DISCUSSION}

A number of prognostic factors were analysed in relation to the median overall survival rate. The analysis found that the greater percentage of maximal cytoreduction achieved among the cohorts was associated with an improved overall survival rate $(\mathrm{p}=0.046)$. For every $10 \%$ 
Table 3. Outcomes following no debulking surgery.

\begin{tabular}{cl}
\hline Author & \multicolumn{1}{c}{ Outcome following no debulking surgery } \\
\hline Ansquer [13] & 4 patients died before 3 cycles of chemo \\
Kuhn [15] & 1 patient had a PE \\
Ushijima [17] & 2 patients did not receive chemo due to poor prognosis, 18 received chemo, 3 refused surgery - all died \\
Mazzeo [19] & 1 patient had IHD, 1 refused surgery + died, 3 had disease progression \\
Loizzi [21] & 5 patients had disease progression + died within 6 months \\
Hou [30] & 1 patient due to co-morbidities - remained disease free, 1 had disease progression and died within 9 months \\
Ghaemmaghami [33] & 4 patients had disease progression \\
\hline
\end{tabular}

increase in percentage optimal debulking there was a 2.28 month increase in the survival rate. This is consistent with a number of studies and it is now commonly accepted that optimal debulking surgery is the single best prognostic indicator for overall survival.

The addition of taxane to the chemotherapy regime was also found to improve the overall survival ( $\mathrm{p}=$ 0.019 ). For every $10 \%$ increase in taxane use there was a 1.27 month increase in the overall survival rate. However there was no association between the number of chemotherapy cycles and survival rates which differed from a previous meta-analysis by Bristow et al. that found a significant association [37].

The percentage stage IV disease did show the expected decrease in the overall survival rate with an increase in the percentage stage IV disease but this was not a significant trend. This may have been because the remaining patients had extensive stage IIIC disease which is associated with a poor survival rate and therefore survival rates between stage IIIC and IV may not be dissimilar.

For every year increase in publication there was a statistically significant increase in the overall survival rate (1.46 months). The mean percentage maximal cytoreduction was similar between 2000-2005 and 2006-2010 (69.5\% and $69.8 \%$ ) but the definition of optimal debulking as $<1 \mathrm{~cm}$ became much more acceptable. With 38\% of cohorts defining optimal debulking as $<1 \mathrm{~cm}$ between 2000-2005 and 69\% between 2006-2010. This change in definition of optimal debulking combined with similar cytoreduction rates is a possible reason for the improved survival rates over time.

The mean of the median age was 60.4 years among the cohorts. There was a negative correlation $(r=-0.21)$ between age and the overall survival rate but not a statistically significant association ( $p=0.312$ ). A more useful measurement would have been the performance status of patients as this is more likely to be associated with a poor survival rate than increased age.

In comparing centres, there was a better overall survival rate in North America (35.6 months) than both Europe (31.9 months) and Asia (29.8 months). The per- centage optimal cytoreduction achieved was similar in Europe (72.4\%) and North America (71.8\%) but much lower in Asia (61.6\%). This would be a possible explanation for the improved survival rates in North America and Europe compared to Asia but it is difficult to comment further as there were relatively few cohorts and not an equal distribution between regions.

A wide variety of staging procedures were used among the cohorts. Laparoscopy and laparotomy were the most common procedures performed with 14 out of the 20 cohorts using either procedure.

Pre-operative severity and residual tumour site were poorly recorded among the cohorts with only 6 of the 26 cohorts and 3 of the 26 cohorts respectively recording the relevant data. It is therefore difficult to analyse due to the limited data. There was a wide range of upper abdominal disease pre-operatively $(6.6 \%-55.6 \%)$ and the cohort with $55.6 \%$ of abdominal disease was associated with the lowest overall survival rate of 18 months.

Residual tumour site following debulking surgery cannot be reliably analysed as so few cohorts recorded this information. It would have been interesting to compare the pre-operative severity with both the optimal debulking achieved and the overall survival rate. Also to be able to correlate the cohorts that had a poor optimal debulking percentage with the site of residual tumour. We know that upper abdominal disease is associated with a reduced likelihood of achieving complete cytoreduction.

The percentage of patients who did not go on to have debulking surgery ranged from $0 \%-53.3 \%$. The reason why debulking surgery was not performed was not routinely mentioned among the cohorts. The cohort with $53.3 \%$ of patients not going on to have debulking surgery had a high overall survival rate of 45.5 months. However this may have been because $77.3 \%$ in the cohort achieved maximal debulking and only $18 \%$ had stage IV disease. The outcome of patients who had no debulking surgery was poorly recorded with only 7 cohorts noting the outcome.

The percentage of bowel resection performed among the cohorts did not correspond to an increase in survival 
rates. There was in fact a decrease in the survival rate of 1.4 months for every $10 \%$ increase in bowel resection but this was not statistically significant $(p=0.606)$. However in the cohorts that performed bowel resections there was a greater percentage of optimal debulking achieved (74.2\%) compared to the cohorts that did not perform bowel surgery (62.5\%). There was also a much higher percentage of Stage IV disease among the cohorts that performed bowel surgery (28.7\%) compared to those that did not (16.7\%). The greater percentage of Stage IV disease in some cohorts meant that there were a greater number of patients with widespread and extensive disease. Bowel resection may have been necessary in some cohorts more than others in an effort to achieve optimal debulking. This may be a possible explanation for why there was a slight decrease in the survival rate in those cohorts that performed bowel surgery as a greater number of patients had extensive disease before debulking surgery was attempted. It is also unclear whether a specialist or a general surgeon performed the bowel surgery within the cohorts.

Most experts believe that the less residual disease present after surgery the better the overall survival rate. The question still remains how radical and aggressive should surgeons be in an effort to achieve 'optimal' debulking. If optimal cytoreduction is achieved this does not however mean the patient will have a similar survival rate than a patient who initially had disease less than $1 \mathrm{~cm}$ without cytoreduction. This is supported by Hoskins et al. who showed that patients with large volume disease with optimal debulking did not have a similar survival rate to those patients who presented with small volume disease [38]. It has been suggested that large volume disease may have a more aggressive pathology than small volume disease and this requires further study.

In this meta-analysis, ultra radical surgery was performed in six cohorts in an effort to achieve optimal debulking. Only 9 cohorts recorded if ultra radical surgery was performed or not. A wide range of procedures were performed including splenectomies, liver resections and pancreatectomies. The percentage achieving maximal debulking among the cohorts that performed ultra radical surgery ranged from $48.1 \%$ to $100 \%$ with a mean of $78.5 \%$.

The mean overall survival rate among the cohorts that had ultra radical surgery was 29.6 months which is below the overall mean of all cohorts of 32.1 months. The range of overall survival rates among these cohorts was 22 - 46 months. The reason for the one study that had a survival rate of 46 months was unclear as no patient had a splenectomy, pancreatectomy or liver resection in this cohort however optimal debulking was achieved in 95.3\% of patients. The overall survival rate of 29.6 months could be less than the mean of all the cohorts as the effort to achieve optimal debulking may be associated with extensive morbidity. The post-operative complications were not recorded from the cohorts and this would have been useful to compare morbidity associated with ultra radical surgery and lymphadenectomy. The data regarding ultra radical surgery is however difficult to interpret and analyse as it was performed in so few studies and further research needs to be done to establish any benefit.

This meta-analysis has not looked at the use of CA125 monitoring in terms of resectability and prognosis, however a number of studies have suggested it may be a useful indicator. It is widely accepted that CA-125 levels decrease during first line chemotherapy and is associated with a better prognosis [39]. A study by Bilici et al. [36] showed that following neoadjuvant chemotherapy, a statistically significant decrease in CA-125 levels was determined and this is consistent with similar studies following adjuvant chemotherapy.

CA-125 levels have failed to be precise and reliable in determining the resectability of advanced ovarian cancer. However studies have shown that a CA-125 that does not normalise following neoadjuvant chemotherapy is associated with a worse outcome. An alternative more reliable method may be the use of laparoscopy routinely to establish the severity of disease prior to undertaking debulking surgery.

CT scan criteria for determining the resectability of the tumour has been reported to be a reliable indicator. Qayyum et el found that pre-operative CT and MRI were equally accurate in detecting inoperable disease with a positive predictive value of $94 \%$ and a negative predictive value of $96 \%$ [40]. There is however no uniformly accepted CT scan criteria for predicting resectability.

The ascites volume has been shown by Kuhn et al. [15] to have an influence on the survival rate and tumour resectability. The ascites volume is often associated with extensive and diffuse peritoneal disease and the measurement of ascites volume alongside other investigations may well be useful in the prediction of tumour resectability.

This meta-analysis did not show a statistical significant association between lymphadenectomy and the overall survival rate $(p=0.813$ ) however less than half the cohorts recorded whether lymphadenectomy was performed or not. This was consistent with a RCT by Panici et al. that noted an improved progression free survival but not overall survival in women following a systematic lymphadenectomy [41].

A much reported hypothesis is that lymph node involvement in ovarian cancer is chemoresistant and is often termed a 'sanctuary' site with regards to its response to chemotherapy. A possible explanation for this resistance 
from Eisenkop et al. is that retroperitoneal nodal metastases have a reduced blood supply compared to intraabdominal disease and this results in lower levels of cytotoxic agents reaching the nodes [42]. It is unclear if the poor prognosis of patients with positive lymph nodes is due to the tumour's aggressiveness or that nodal involvement is resistant to chemotherapy [43].

Lymphadenectomy is commonly performed outside the UK however within the UK very few centres perform the procedure routinely. The recent pre-publication from the National Institute for Health and Clinical Excellence (NICE) (Guideline February 2011) does not mention the role of systematic lymphadenectomy in advanced ovarian cancer which suggests it may be a while before the procedure becomes common practice within the UK [44].

The recent study by Vergote et al. [4] in September 2011 was the first randomised control trial comparing primary debulking surgery followed by chemotherapy versus neoadjuvant chemotherapy followed by debulking surgery. The study concluded that neoadjuvant chemotherapy followed by interval debulking was not inferior to the standard primary debulking surgery in the treatment of advanced ovarian cancer. However both groups had little or no upper abdominal surgery performed. This may have been a coincidence with relatively few patients requiring the surgery or due to the aggressiveness of the debulking surgery. Either way this will have influenced the overall survival rate compared to other studies where there are a higher percentage of upper abdominal surgery often associated with a poorer prognosis.

The study also had a wide variability between the rate of optimal and complete cytoreduction. With the range for complete cytoreduction at primary debulking between $3.9 \%$ and $62.9 \%$. This again would be expected to influence the overall survival rate.

The number of cohorts included in this meta-analysis made a multiple linear regression analysis difficult so there was the potential for interactions between variables. There will have been a degree of selection bias but there was a strict inclusion criteria. However the criteria for neoadjuvant chemotherapy administration varied across the cohorts with some studies using CT imaging and other cohorts using laparoscopy or laparotomy to assess the disease severity and need for chemotherapy.

The studies included in the meta-analysis were not all of the highest quality. There was only one randomised control study done on the subject and therefore a systematic review including only randomised control trials was not possible.

Additional prognostic factors that may have influenced survival rates were not examined and these included preoperative CA-125 levels, ascitic volume and performance status. In further studies it would be interesting to record post-operative complications within each cohort to compare whether the aggressiveness of debulking surgery is associated with additional morbidity.

This meta-analysis has shown a number of important prognostic factors that influence survival rates in patients that have had neoadjuvant chemotherapy followed by debulking surgery. The recent RCT by Vergote et al. has shown that neoadjuvant chemotherapy is not inferior to the traditional primary cytoreduction. Therefore it is likely that neoadjuvant chemotherapy will have an increasing role in the future management of advanced ovarian cancer. The results from the CHORUS trial are awaited to see if they support these findings. Further research will need to address the issue of identifying patients that are suitable for neoadjuvant chemotherapy or primary cytoreduction. This may be a combination of CT findings, pre-operative CA-125 levels, ascitic volume or performance status that can predict the resectability of the disease.

\section{CONTRIBUTION TO AUTHORSHIP}

MJF is the first and main author of the manuscript. MJF conceived and designed the manuscript and analysed the data. NAS contributed to interpretation of the data and assisted in the preparation of the article.

\section{DETAILS OF ETHICS APPROVAL/FUNDING}

This is a review of the literature, so no ethical approval was required. No funding source was involved.

\section{ACKNOWLEDGEMENTS}

This paper was submitted as part of an e-dissertation in May 2010 for the Edinburgh Surgical Sciences Qualification (ESSQ). The ESSQ is a 3 year distance learning programme leading to a Masters in Surgical Sciences (www.essq.rcsed.ac.uk).

\section{REFERENCES}

[1] Pomel, C., Barton, D.P.J., McNeish, I. and Shepherd, J. (2008) A statement for extensive primary cytoreductive surgery in advanced ovarian cancer. An International Journal of Obstetrics and Gynaecology, 115, 808-810. doi:10.1111/j.1471-0528.2008.01692.x

[2] Hariprasad, R., Kumar, L. and Kapoor, A. (2007) Neoadjuvant chemotherapy for advanced ovarian cancereditorial. Indian Journal of Medical \& Paediatric Oncology, 28, 4-5.

[3] Scottish Intercollegiate Guidelines Network (SIGN) (2003) Epithelial ovarian cancer, Clinical Guideline 75.

[4] Vergote, I., Trope, C.G. and Armant, F. (2010) Neoadjuvant chemotherapy or primary surgery in stage IIIC or IV ovarian cancer. The New England Journal of Medicine, 363, 943-953. doi:10.1056/NEJMoa0908806

[5] Allen, D.G., Heintz, A.P. and Touw, F.W. (1995) A 
meta-analysis of residual disease and survival in stage III and IV carcinoma of the ovary. European Journal of Gynaecologic Oncology, 16, 349-356.

[6] Morrison, J., Swanton, A., Collins, S. and Kehoe, S. (2007) Chemotherapy versus surgery for initial treatment in advanced ovarian epithelial cancer. Cochrane Database of Systematic Reviews, 4, CD005343. doi:10.1002/14651858.CD005343.pub2

[7] Venesmaa, P. and Ylikorkala, O. (1992) Morbidity and Mortality associated with primary and repeat operations for ovarian cancer. Obstetrics \& Gynecology, 79, 168172.

[8] Gerestein, C.G., Damhuis, R.A., Burger, C.W. and Kooi, G.S. (2009) Postoperative mortality after primary cytoreductive surgery for advanced stage epithelial ovarian cancer: A systematic review. Gynecologic Oncology, 114, 523-527. doi:10.1016/j.ygyno.2009.03.011

[9] Aletti, G.D., Long, H.J., Podratz, K.C. and Cliby, W.A. (2007) Is time to chemotherapy a determinant of prognosis in advancedstage ovarian cancer? Gynecologic Oncology, 104, 212-216. doi:10.1016/j.ygyno.2006.07.045

[10] Gadducci, A., Sartori, E., Landoni, F., et al. (2005) Relationship between time interval from primary surgery to the start of taxaneplus platinum-based chemotherapy and clinical outcome of patients with advanced epithelial ovarian cancer: Results of a multicenter retrospective Italian study. Journal of Clinical Oncology, 23, 751-758. doi:10.1200/JCO.2005.03.065

[11] Chan, Y.M., Ng, T.Y., Ngan, H.Y. and Wong, L.C. (2003) Quality of life in women treated with neoadjuvant chemotherapy for advanced ovarian cancer: A prospective longitudinal study. Gynecologic Oncology, 88, 9-16. doi:10.1006/gyno.2002.6849

[12] Moher, D., Liberati, A., Tetzlaff, J. and Altman, D.G. (2009) PRISMA group. preferred reporting items for systematic reviews and meta-analyses: The PRISMA statement. British Medicine Journal, 339, b2535. doi:10.1136/bmj.b2535

[13] Ansquer, Y., Leblanc, E., Clough, K., Morice, P., Dauplat, J., Mathevet, P., et al. (2001) Neoadjuvant chemotherapy for unresectable ovarian carcinoma. Cancer, 91, 2329-2334. doi:10.1002/1097-0142(20010615)91:12<2329::AID-CN CR1265>3.0.CO;2-U

[14] Kayikciog, F., Kose, M.F., Boran, N., Caliskan, E. and Tulunay, G. (2001) Neoadjuvant chemotherapy or primary surgery in advanced epithelial ovarian carcinoma. International Journal of Gynecological Cancer, 11, 466-470. doi:10.1046/j.1525-1438.2001.01064.X

[15] Kuhn, W., Rutke, S., Späthe, K., Schmalfeldt, B., Florack, G. and Von, H.B. (2001) Neoadjuvant chemotherapy followed by tumor debulking prolongs survival for patients with poor prognosis in International Federation of Gynecology and Obstetrics stage IIIC ovarian carcinoma. Cancer, 92, 2585-2591. doi:10.1002/1097-0142(20011115)92:10<2585::AID-CN CR1611>3.0.CO;2-\#

[16] Vrščaj, M.U. and Rakar, S. (2002) Neoadjuvant chemotherapy for advanced epithelial ovarian carcinoma: A retrospective case-control study. European Journal of Gynaecolocal Oncology, 23, 405-410.
[17] Ushijima, K., Ota, S., Komai, K., Matsuo, G., Motoshima, S., Honda, S., et al. (2002) Clinical assessment of neoadjuvant chemotherapy and interval cytoreductive surgery for unresectable advanced ovarian cancer. International Surgery, 87, 185-190.

[18] Morice, P., Dubernard, G., Rey, A., Atallah, D., Pautier, P., Pomel, C., et al. (2003) Results of interval debulking surgery compared with primary debulking surgery in advanced stage ovarian cancer. Journal of the American Colloge of Surgeons, 197, 955-963. doi:10.1016/j.jamcollsurg.2003.06.004

[19] Mazzeo, F., Berlière, M., Kerger, J., Squifflet, J., Duck, L., D’Hondt, V., et al. (2005) Neoadjuvant chemotherapy in patients with primarily unresectable, advancedstage ovarian cancer. Gynecolocal Oncology, 23, 74457453.

[20] Fanfani, F., Ferrandina, G., Corrado, G., Fagotti, A., Zahut, H.V., Mancuso, S., et al. (2002) Impact of interval debulking surgery on clinical outcome in primary unresectable FIGO stage IIIC ovarian cancer patients. Oncology, 65, 316-322. doi:10.1159/000074644

[21] Loizzi, V., Cormio, G., Rossi, C.A., Di, G.A.R., Cuccovillo, A. and Selvaggi, L. (2005) Neoadjuvant chemotherapy in advanced ovarian cancer: A case-control study. International Journal of Gynecological Cancer, 15, 217-223. doi:10.1111/j.1525-1438.2005.15206.x

[22] Le, T., Faught, W., Hopkins, L. and Fung, M.F.K. (2005) Primary chemotherapy and adjuvant tumor debulking in the management of advanced-stage epithelial ovarian cancer. International Journal of Gynecological Cancer, 15, 770-775. doi:10.1111/j.1525-1438.2005.00134.x

[23] Hegazy, M.A.F., Hegazi, R.A.F., Elshafei, M.A., Setit, A.E., Elshamy, M.R., Eltatoongy, M., et al. (2005) Neoadjuvant chemotherapy versus primary surgery in advanced ovarian carcinoma. World Journal of Surgery Oncology, 3, 57-64. doi:10.1186/1477-7819-3-57

[24] Avril, N., Sassen, S., Schmalfeldt, B., Naehrig, J., Rutke, S., Weber, W.A., et al. (2005) Prediction of response to neoadjuvant chemotherapy by sequential F-18-fluorodeoxyglucose positron emission tomography in patients with advancedstage ovarian cancer. Jouanl of Clinical Oncology, 23, 7445-7453. doi:10.1200/JCO.2005.06.965

[25] Everett, E.N., French, A.E., Stone, R.L., Pastore, L.M., Jazaeri, A.A., Anderson, W.A., et al. (2006) Initial chemotherapy followed by surgical cytoreduction for the treatment of stage III/IV epithelial ovarian cancer. American Jouranl of Obstetrics and Gynecology, 195, 568576. doi:10.1016/j.ajog.2006.03.075

[26] Lee, S., Kim, B., Lee, J., Park, C., Lee, J. and Bae, D. (2006) Preliminary results of neoadjuvant chemotherapy with paclitaxel and cisplatin in patients with advanced epithelial ovarian cancer who are inadequate for optimum primary surgery. Journal of Obstetrics and Gynecology, 32, 99-106.

[27] Inciura, A., Simavicius, A., Juozaityte, E., Kurtinaitis, J., Nadisauskiene, R., Svedas, E., et al. (2006) Comparison of adjuvant and neoadjuvant chemotherapy in the management of advanced ovarian cancer: A retrospective study of 574 patients. Biomed Central, 6, 153. doi:10.1186/1471-2407-6-153

[28] Deo, S.V.S., Goyal, H., Shukla, N.K., Raina, V., Kumar, L., 
Srinivas, G., et al. (2006) Neoadjuvant chemotherapy followed by surgical cytoreduction in advanced epithelial ovarian cancer. Indian Journal of Cancer, 43, 117-121. doi:10.4103/0019-509X.27933

[29] Le, T., Alshaikh, G., Hopkins, L., Faught, W. and Fung, M.F.K. (2006) Prognostic significance of postoperative morbidities in patients with advanced epithelial ovarian cancer treated with neoadjuvant chemotherapy and delayed primary surgical debulking. Annuals of Surggical Oncology, 13, 1711-1716. doi:10.1245/s10434-006-9125-6

[30] Hou, J.Y., Kelly, M.G., Yu, H., McAlpine, J.N., Azodi, M., Rutherford, T.J., et al. (2007) Neoadjuvant chemotherapy lessens surgical morbidity in advanced ovarian cancer and leads to improved survival in stage IV disease. Gynecological Oncology, 105, 211-217. doi:10.1016/i.ygyno.2006.11.025

[31] Rafii, A., Deval, B., Geay, J.F., Chopin, N. and Paoletti, X., Paraiso, D., et al. (2007) Treatment of FIGO stage IV ovarian carcinoma: Results of primary surgery or interval surgery after neoadjuvant chemotherapy: A retrospective study. International Journal of Gynecological Cancer, 17, 777-783. doi:10.1111/j.1525-1438.2007.00905.x

[32] Rosa, D.D., Ton, N.C., Clamp, A., Mullamitha, S., Lau, S., Clayton, R., et al. (2007) The neoadjuvant approach in the treatment of patients with advanced epithelial ovarian carcinoma. Clinical Oncology, 19, 125-128. doi:10.1016/j.clon.2006.11.015

[33] Ghaemmaghami, F., Karimi-Zarchi, M., Modares-Gilani, M., Mousavi, A. and Behtash, N. (2008) Clinical outcome of Iranian patients with advanced ovarian cancer with neoadjuvant chemotherapy versus primary debulking surgery. Asian Pacific Journal of Cancer Prevention, 9, 719-724.

[34] Suprasert, P., Tiyanon, J. and Kietpeerakool, C. (2008) Outcome of interval debulking in advanced ovarian cancer patients. Asian Pacific Journal of Cancer Prevention, 9, 519-524.

[35] Pölcher, M., Mahner, S., Ortmann, O., Hilfrich, J., Diedrich, K., Breitbach, G., et al. (2009) Neoadjuvant chemotherapy with docetaxel in advanced ovarian cancer-a prospective multicenter phase II trial (PRIM OVAR). Oncologu Reports, 22, 605-613.

[36] Bilici, A., Salepci, T., Dane, F., Gumus, M., Ustaalioglu, B.B.O., Seker, M., et al. (2010) Neoadjuvant chemotherapy followed by interval cytoreductive surgery in patients with unresectable, advanced stage epithelial ova- rian cancer: A single centre experience. Archives of Gynecology and Obstetics, 282, 417-425.

doi:10.1007/s00404-009-1330-7

[37] Bristow, R.E. and Chi, D.S. (2006) Platinum-based neoadjuvant chemotherapy and interval surgical cytor-eduction for advanced ovarian cancer: A meta-analysis. Gynecological Oncology, 103, 1070-1076. doi:10.1016/j.ygyno.2006.06.025

[38] Hoskins, W.J., Bundy, B.N., Thigpen, J.T. and Omura, G.A. (1992) The influence of cytoreductive surgery on recurrence-free interval and survival in small-volume stage III epithelial ovarian cancer: A gynaecologic oncology group study. Gynecological Oncology, 47, 159166. doi:10.1016/0090-8258(92)90100-W

[39] Pecorelli, S., Odicino, F. and Favalli, G. (2002) Interval debulking surgery in advanced epithelial ovarian cancer. Best Practice and Research Clinical Obstetrics and Gynaecology, 16, 573-583. doi:10.1053/beog.2002.0302

[40] Qayyum, A., Coakley, F.V., Westphalen, A.C., Hricak, H., Okuno, W.T. and Powell, B. (2005) Role of CT and MR imaging in predicting optimal cytoreduction of newly diagnosed primary epithelial ovarian cancer. Gynecological Oncology, 96, 301-306. doi:10.1016/j.ygyno.2004.06.054

[41] Panici, P.B., Maggioni, A., Hacker, N., Landoni, F., Acker-Mann, S., Campagnutta, E., et al. (2005) Systematic aortic and pelvic lymphadenectomy versus resection of bulky nodes only in optimally debulked advanced ovarian cancer: A randomized clinical trial. Journal of the National Cancer Institue, 97, 560-566. doi:10.1093/jnci/dji102

[42] Eisenkop, S.M. and Spirtos, N.M. (2001) The clinical significance of occult macroscopically positive retroperitoneal nodes in patients with epithelial ovarian cancer. Gynecological Oncology, 82, 143-149. doi:10.1006/gyno.2001.6232

[43] Kim, H.S., Ju, W., Jee, B.C., Kim, Y.B., Park, N.H. and Song, Y.S. (2010) Systematic lymphadenectomy for survival in epithelial ovarian cancer: A meta-analysis. International Journal of Gynecological Cancer, 20, 520528. doi:10.1111/IGC.0b013e3181d6de1d

[44] National Institute for Health and Clinical Excellence (NICE) (2011) Ovarian cancer: Full guideline for prepublication check. 